AGH DRILLING, OIL, GAS • Vol. 32 • No. $2 \cdot 2015$

http://dx.doi.org/10.7494/drill.2015.32.2.359

Florinel Şuțoiu*, Ion Foidaş*, Mihail Avramescu*

\title{
INCREASING THE DEGREE OF CERTAINTY ON DEPLETED GAS RESERVOIR PERFORATION, USING GEOPHYSICAL SATURATION METHODS
}

\section{INTRODUCTION}

Increasing the degree of certainty on the gas reservoirs, was always a purpose of the companies to develop and to increase the profitability of the reservoirs.

When we talk about depleted reservoirs becomes necessary to increase the certainty of the information we obtain about reservoirs.

Imagine trying to sense the temperature of a thing or to sense the texture of a rock wearing insulated gloves. Measuring rock properties using logging tools is equally difficult when the formation is on the other side of steel casing and cement. Significant software and tool developments now make possible good evaluation of formations behind casing.

Advanced formation-evaluation services help E\&P (exploration and production companies), search for additional or initially unrecognized zones and identify bypassed hydrocarbons after casing is set. These innovative, cased hole investigation methods facilitate determining porosity, lithology, shale content, fluid saturations and pressure. These geophysical investigation methods also offer valuable data when looking for bypassed pay in older wells, or when monitoring saturation, depletion and pressure to optimally manage gas fields.

Therefore one of the major objective of the companies is to obtain eloquent information about reservoirs using and implementing these new geophysical investigation methods in cased holes, all aimed at rehabilitating wells in production and maintaining a good level of production.

* SNGN ROMGAZ SA 
The new investigation methods are run to assess well integrity, improve reservoir management, and scan the well for bypassed production before plugging and abandoning. These investigations are also key diagnostic tool for workover planning and operations.

In most older producing wells, cased holes logs are all that can be run. Traditional reasons include diagnosing the illness of old wells, wells which may now produce excessive amounts of water. Cased hole logs shed light on the sources of water and hydrocarbon production downhole and offer hope that such production restorations may be possible. Also, logs are frequently run in casing to monitor the reservoir so that changes in production can be anticipated and planned for. Such monitoring is commonly done to detect movement of water-oil or gas oil contacts during production in individual wells and thereby help manage overall reservoir production among a number of wells. Saturation changes at unanticipated locations may dictate selectively perforating new intervals to assure proper reservoir depletion.

Sometimes, old wells are logged for the purpose of detecting bypassed producible zones, typically uphole from current or recently produced zones. This occurs when old wells do not have a good suite of open hole logs available, or such bypassed production was not detectable using old older logging or interpretation techniques. Perhaps such upper zones are gas and were not of interest at the time of initial completion. Locating such bypassed production will provide new reserves to a company from assets thought to be depleted and worthless.

Therefor cased hole $\operatorname{logs}$ are the diagnostic tools for efficient reservoir management

and production. So, in order to estimate the lithology, effective porosity and remaining fluid saturation behind the casing, we used geophysical methods as CRE (Raptor N-Vision) or PNN (Pulsed Neutron-Neutron) in some wells in production.

This geophysical investigations, are capable of highlight the most thin gas saturated layers, offering for depleted gas reservoirs a new chance.

Lately ROMGAZ, used most types of anterior mentioned investigations, in purpose of analyzing the petrophysical properties of thin sands.

Thereby, there had been identified within depleted gas reservoirs, many layers saturated with gas, which after perforation had been confirmed.

After, these were included in the effective thickness zone, constitute the foundation for gas resources and reserves reevaluations.

In what follows below, will be presented some concrete examples regarding the usage of these high resolution logs, for a better definition of reservoir properties.

\section{PULSED NEUTRON-NEUTRON METHOD (PNN)}

Open hole neutron tools used in investigations utilize a chemical source which constantly emit neutrons. 
Pulsed neutron tools use an electronically triggered neutron generator which can be switched on or off (pulsed).

Imagine a cloud of neutrons being pumped into the formation, the generator being shut off and then the cloud of neutrons undergoing various reactions and eventually being completely 'absorbed'.

The time of this 'absorption' or decay varies, depending on the actual elements present (i.e. water vs. hydrocarbons).

By recording this decay rate, and calculating the slope of this rate, we can identify what element we are actually measuring at that instance in time.

The characteristic slope of this decay is called Sigma, which is the macroscopic thermal neutron absorption cross section and is measured in capture units.

Sigma is proportional to the slope of the curve in logarithmic scale. With sigma, saturations and shale volumes can be calculated. Porosity can also be calculated when calibrated to $\mathrm{OH}$ Neutron data. Qualitatively, Gas/Oil, Gas/Water and Oil/Water contacts can be determined.

The PNN tool measures Sigma, the ability of material to capture thermal Neutrons, in capture units (c.u.).

PNN counts directly the thermal neutrons reaching the detectors after their interaction with the surrounding formation; then, the usual inference by common Thermal decay tools that count Gamma Rays where High-counts means high-Sigma-Values changes by the PNN tool into High-counts means Low-Sigma-Values, and it has the significance of obtaining statistical uncertainties reduction for low Sigma values. This sole measuring approach allows better differentiation in environments of low Sigma values, which is the case when fresh water, oil and/or gas are present in the pore spaces, overcoming by this way, the low salinity formation water problem which appears as a limitation factor of standard Thermal Decay Time tools; additionally, Neutron readings are less affected by Neutron activation, hence, logging of Time-driven Stop-Checks in area of interest helps reduce the statistical uncertainties of readings at any desired depth spot. All of this makes PNN tool, in conjunction with PNN processing and analysis, a competitive behind-casing formation evaluation tool for high to moderate water salinity formations and the ultimate thermal decay tool for evaluation of lower salinity and lower porosity formations.

The formation is bombarded with pulses of high-energy neutrons $(14 \mathrm{MeV})$ generated by the tool. Neutrons interact with the surrounding atoms and, during the lapse of time between high-energy neutron pulses, the thermal neutron population that reaches the Neutron detectors is sampled by two detectors with 60 time channels each; Per Channel Neutrons counted are used to compute the rate of decay, it is equivalent to measuring the rate at which thermal neutrons are absorbed into the formation, the greater fluids and minerals capture thermal neutrons, the higher the value of Sigma. 
Concluding, this type of investigation:

- is less dependent on the fluid type in the borehole to deliver accurate results;

- is an excellent Gas Indicator;

- is an excellent Porosity Indicator;

- have been attained excellent results in salinities as low as $4000 \mathrm{ppm}$ and porosities low as $6 \%$;

- allows you to differentiate between gas/water/oil with confidence because of the higher accuracy of the $\log$.

\section{THE CRE METHOD (RAPTOR N-VISION)}

From approximately 1970 until 2003, a period of about 33 years, the only modes of operation and measurement for pulsed neutron instruments for formation evaluation measurements was the sigma measurement and the Carbon/Oxygen measurement. This changed in 2003 when Baker Hughes introduced GasView, a measurement of formation gas saturation made without using sigma or $\mathrm{C} / \mathrm{O}$. Using this measurement method it is possible to make gas and liquid saturation measurements without using sigma or $\mathrm{C} / \mathrm{O}$ measurements.

The method may be intuitively understood by considering the following thought experiment. Suppose that you put the tool on the floor of your office and turned on the generator. Would you stay in the room with the generator producing about 100 million, 50-million mph neutrons per second? No, you would not. You would leave the office and probably leave the building. But wait a minute. If you put the tool in a water tank, or waterfilled formation tank about 5-feet in diameter, you would walk right up to it and stand next to it. What's the difference?

When you remove the liquid from the porosity and replace it with air or gas the neutrons and gamma rays go a lot further! This is pretty easy to visualize, and it is exactly what happens. The neutrons and gammas see the large change in the density of the material in the pore space and react to the low density of the gas by traveling much farther.

Thus, if you want to detect the gas, use a detector that is further away from the generator as it will show the most increase in count rate when the gas is present. Actually the near detector count rates increase also, so the best way to observe the gas presence is to measure a ratio of the nearest detector to the farthest detector during the neutron burst, in our case the proximal to long ratio. This curve is called VB15 (B15 means "ratio of 1:5 during the burst"). This curve can be characterized to not only identify gas but also to calculate how much gas is present, the gas saturation.

Now, it is intuitively easy to see that the VB15 ratio can tell the difference in the density of water in the pore space and the density of gas since there is such a large difference in their densities.

The mode of pulsing that is used to measure VB15 is called N-Vision. It consists of a 200-microsecond burst width and a fixed 1200-microsecond hiatus following the burst. This N-Vision mode is then mixed $80 \%$ to $20 \%$ of the sigma mode because the background correction is made during the sigma burst. 
Concluding:

Raptor N-Vision Measurement (Gas Saturation Measurement)

- Measurement method not based on CO or Sigma.

- Saturations are determined by measuring pore fluid density.

\section{EXAMPLES OF WELLS INVESTIGATED WITH THESE METHODS}

\subsection{Well A (Investigated with PNN)}

Investigation with PNN was made at well A on 1500.0-1860.0 m range.

Well depth: $1864 \mathrm{~m}$.

Casing: $-85 / 8 "$ at $436.0 \mathrm{~m}$, $-51 / 2^{\prime \prime}$ at $2338.0 \mathrm{~m}$.

Properties of the reservoir represented by porosity and salinity are presented in Table 1.

Table 1

Average porosity and salinity data

\begin{tabular}{|l|c|c|c|c|}
\hline \multicolumn{1}{|c|}{ Complex } & Top $[\mathrm{m}]$ & Base [m] & Porosity [\%] & Salinity [g/l] \\
\hline Sarmatian X & 1500.0 & 1518.0 & 15.1 & 97 \\
\hline Sarmatian XI & 1518.0 & 1624.0 & 10.7 & 66 \\
\hline Sarmatian XII & 1624.0 & 1677.0 & 10.1 & 66 \\
\hline Sarmatian XIII & 1677.0 & 1772.0 & $8.5-15.5$ & 91 \\
\hline Sarmatian XIV & 1772.0 & 1860.0 & $12.4-18.3$ & 105 \\
\hline
\end{tabular}

Layer in production after workover: Sarmatian XIV.

Flow after investigation and workover: $Q=15800 \mathrm{~cm} / \mathrm{d}$.

Perforations: $1775.0-1801.0 \mathrm{~m}$.

\section{Analysis results}

After the PNN investigation aiming to evaluate the formation and the fluid content in the pores of rock, petrophysical parameters were calculated in Table 2. These parameters characterize the reservoir rock in terms of hydrocarbon accumulations (Fig. 1).

Table 2 shows the medium values of possible productive intervals ("pay zones") estimated for these limiting values:

- clay volume $-V_{\text {clay }} \leq 45 \%$,

- effective porosity - PHIE $\geq 5 \%$,

- water saturation $-S w \leq 60 \%$. 
Table 2

Results of PNN investigation at Well A

\begin{tabular}{|c|c|c|c|c|c|c|c|c|c|}
\hline $\begin{array}{c}\text { No. } \\
\text { crt }\end{array}$ & $\begin{array}{c}\text { Zones } \\
{[\mathrm{m}]}\end{array}$ & $\begin{array}{c}\text { Top } \\
{[\mathrm{m}]}\end{array}$ & $\begin{array}{c}\text { Bottom } \\
{[\mathrm{m}]}\end{array}$ & $\begin{array}{c}\text { Net } \\
{[\mathrm{m}]}\end{array}$ & $\begin{array}{c}\text { Average } \\
\text { Shale } \\
\text { Volume } \\
{[\mathrm{v} / \mathrm{v}]}\end{array}$ & $\begin{array}{c}\text { Average } \\
\text { Porosity } \\
{[\mathrm{v} / \mathrm{v}]}\end{array}$ & $\begin{array}{c}\text { Average } \\
\text { Water } \\
\text { Saturation } \\
{[\mathrm{v} / \mathrm{v}]}\end{array}$ & $\begin{array}{c}\text { Average } \\
\text { SIGMA } \\
{[\mathrm{c.u} .]}\end{array}$ & Caracterisation \\
\hline 1 & Sa XI & 1558.1 & 1558.2 & 0.1 & 0.44 & 0.1 & 0.58 & 17.6 & possible gas \\
\hline 2 & Sa XII & 1665.6 & 1666.5 & 0.9 & 0.34 & 0.13 & 0.47 & 16.9 & gas \\
\hline 3 & Sa XIII & 1765.1 & 1765.7 & 0.6 & 0.41 & 0.14 & 0.19 & 16.2 & gas \\
\hline 4 & Sa XIV & 1775.5 & 1775.6 & 0.1 & 0.39 & 0.14 & 0.59 & 16.1 & gas \\
\hline 5 & Sa XIV & 1775.8 & 1776.4 & 0.6 & 0.39 & 0.14 & 0.54 & 15.8 & gas \\
\hline 6 & Sa XIV & 1780.9 & 1781.5 & 0.6 & 0.42 & 0.13 & 0.49 & 15.2 & gas \\
\hline 7 & Sa XIV & 1784.2 & 1785.5 & 1.3 & 0.34 & 0.16 & 0.45 & 15.5 & gas \\
\hline 8 & Sa XIV & 1789.0 & 1789.9 & 0.9 & 0.36 & 0.15 & 0.46 & 15.4 & gas \\
\hline 9 & Sa XIV & 1799.3 & 1801.1 & 1.8 & 0.19 & 0.22 & 0.25 & 14.4 & gas \\
\hline 10 & Sa XIV & 1804.6 & 1804.7 & 0.1 & 0.32 & 0.17 & 0.6 & 16.9 & possible gas \\
\hline
\end{tabular}

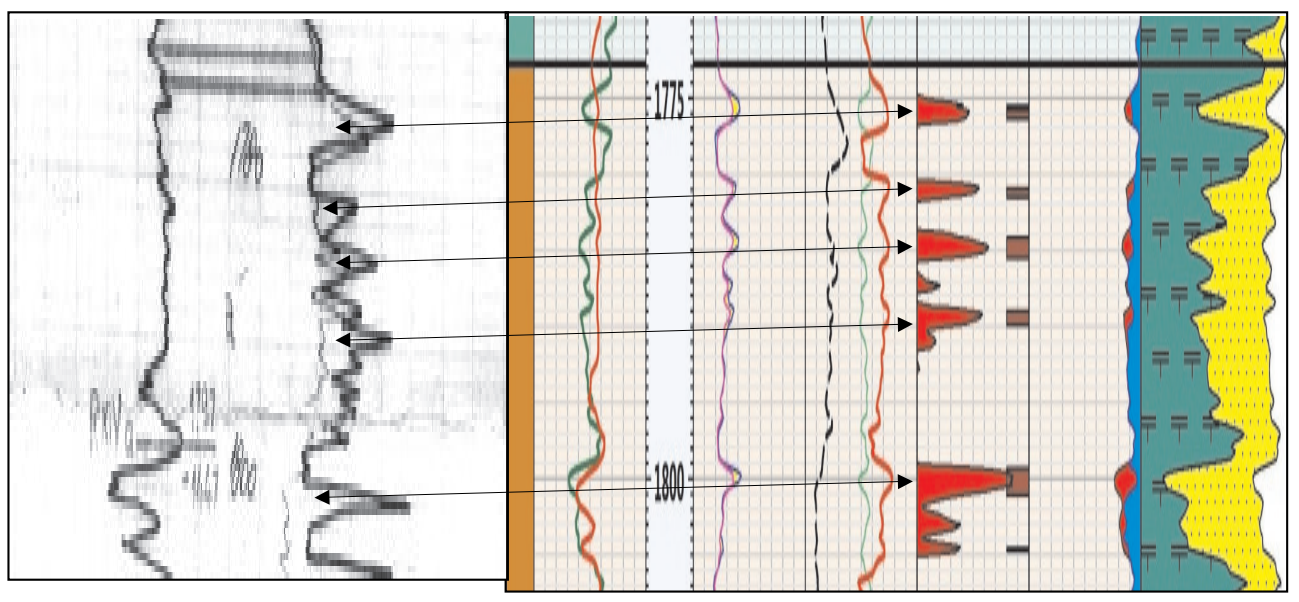

Fig. 1. Standard Electrical Log and PNN Log at well A

\subsection{Well B (Investigated with Raptor N-Vision)}

Investigation with N-Vision Raptor was made at B well on 578.0-1745.0 m range.

Layer: Sarmatian (consists of alternating sandstones, clays and the combination of them: sandstone sandy loam and clay + silt clay).

General properties of the reservoir are represented by low porosity sands the maximum being $22 \%$ while the salinity of the probe is $119 \mathrm{kppm}$ and the density is $1.08 \mathrm{~g} / \mathrm{cc}$. 
In Raptor N-Vision analysis took into account the Transylvanian basin model created, because the probe has not been investigated with complex geophysical measurements in open hole. Thus have created a gas corrected porosity and clay volumes using CRE data based on calibrated model:

- Sarmatian IV (1300-1409 m): salinity $115 \mathrm{kppm}$; porosity 17\%,

- Sarmatian V (1409-1644 m): salinity $163 \mathrm{kppm}$; porosity $18 \%$.

Layer in production after workover: Sarmatian V-VI.

Flow after investigation and workover: $Q=32320 \mathrm{~cm} / \mathrm{d}$.

Perforations: 1620.0-1756.0 m (Fig. 2).

\section{Analysis results}

Gas saturation analysis indicates the following behavior of the gas in the reservoir:

- In investigated interval is observed small saturation in gas in Sarmatian A-IV and large sa-turation in Sarmatian V-VI having the following intervals as the most obvious gas content 1412.6-1438.8 m, 1533.0-1564.8 m, 1629.3-1643.6 m, 1690.4-1697.9 m and $1736.5-1744.4 \mathrm{~m}$, they also present an average gas saturation of $36.4 \%$ and a maximum of $85 \%$.

- So using the applied calibration model there was built a corrected gas porosity that reaches $17.7 \%$ and was determined a maximum saturation of $85 \%$ which is found in the sand layer 1533.0-1564.8 $\mathrm{m}$.

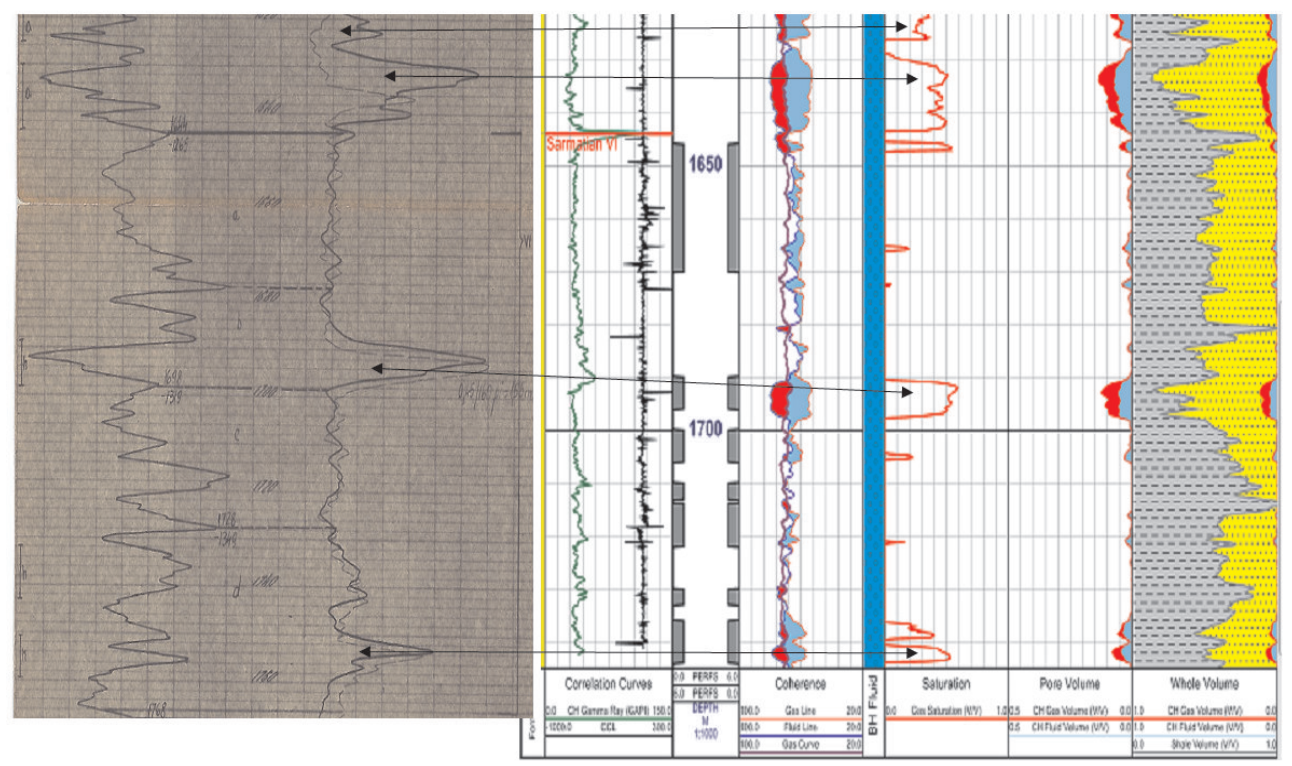

Fig. 2. Standard Electrical Log and CRE Log at well B 


\subsection{Well C (Investigated with $\mathrm{PNN}$ and with Raptor N-Vision)}

Investigation with PNN was made at well $\mathrm{C}$ on 1400.0-1915.0 $\mathrm{m}$ range.

Investigation with N-Vision Raptor was made at well C on 1395.0-1910.0 m range.

Layer in production : Sarmatian (represented by alternation of marls and sands with intercalations of sandstones and tuffs, and marls with intercalations of sand in different proportions).

Well depth: $1934.0 \mathrm{~m}$.

Casing: -8 5/8" at $299.0 \mathrm{~m}$.

$-51 / 2^{\prime \prime}$ at $1945.0 \mathrm{~m}$.

The parameters from Table 3 were used in lithological modeling and fluid analysis.

Table 3

SIGMA Parameters used in PNN Analysis

\begin{tabular}{|l|c|c|c|c|c|}
\hline $\begin{array}{c}\text { Geological } \\
\text { Complex }\end{array}$ & $\begin{array}{c}\text { Matrix } \\
{[\mathrm{cu}]}\end{array}$ & $\begin{array}{c}\text { Shale } \\
{[\mathrm{cu}]}\end{array}$ & $\begin{array}{c}\text { Hydrocarbons } \\
{[\mathrm{cu}]}\end{array}$ & $\begin{array}{c}\text { Water formation } \\
{[\mathrm{cu}]}\end{array}$ & $\begin{array}{c}\text { Water salinity } \\
{[\mathrm{g} / \mathrm{l}]}\end{array}$ \\
\hline Layer X & 17.5 & 20 & 7 & 56 & 95 \\
\hline Layer XI & 12.7 & 20 & 7 & 61.7 & 110 \\
\hline Layer XII & 13 & 23 & 7 & 61.7 & 110 \\
\hline Layer XIII & 14 & 20 & 7 & 56 & 95 \\
\hline Layer XIV & 13 & 20 & 7 & 81.8 & 161 \\
\hline
\end{tabular}

Layer in production after workover: Sarmatian XIII.

Flow after investigation and workover: $Q=11290 \mathrm{~cm} / \mathrm{d}$.

Perforations: 1651.0-1654.0 m,

$1657.0-1659.0 \mathrm{~m}$,

$1668.0-1672.0 \mathrm{~m}$,

$1692.0-1696.0 \mathrm{~m}$,

$1700.0-1712.0 \mathrm{~m}$.

\section{Analysis results (PNN investigation)}

After the analysis the parameters from Table 4 were determined.

Table 4

Parameters determined after PNN analysis at well C

\begin{tabular}{|c|c|c|c|c|c|}
\hline Interval & Description & $\begin{array}{c}\text { VSH } \\
{[\%]}\end{array}$ & $\begin{array}{c}\text { POR } \\
{[\%]}\end{array}$ & $\begin{array}{c}\text { SWPNN } \\
{[\%]}\end{array}$ & $\begin{array}{c}\text { SIGMA } \\
{[\mathrm{cu}]}\end{array}$ \\
\hline $1652.0-1653.2$ & $\begin{array}{c}\text { Aquifer, possible gas, permeability } \\
\text { and low porosity }\end{array}$ & 51.54 & 4.9 & 68.47 & 19.59 \\
\hline $1669.1-1670.4$ & Gas, permeability and low porosity & 61.31 & 4.4 & 56.46 & 17.18 \\
\hline $1701.4-1704.0$ & Gas & 51.04 & 7.6 & 52.84 & 17.27 \\
\hline
\end{tabular}




\section{Analysis results (CRE investigation):}

- It can be observed (Fig. 3) low values of gas saturation throughout the range recorded, emphasizing at $1650.0 \mathrm{~m}$ depth, the presence of gas with saturation values of $60 \%$. On the 1400.0-1775.0 m range are observed some anomalies; surely there is a clear response of measured curve of gas (VB15), but where the porosity decreases we should have a wet zone, not a zone with a high level of gas saturation. There is no reason to have such response, unless there are some laminations, excavation or calculated porosity larger than reality.

- On the 1775.0-1910.0 m range, it can be observed a layer with gas from $1830.0 \mathrm{~m}$ depth to $1853.0 \mathrm{~m}$ depth. Overall, gas saturation is low on the investigated range where most productive layers are washed, flooded, and calculated porosity from CRE have average values of $3 \%$ and the maximum value is $14 \%$.

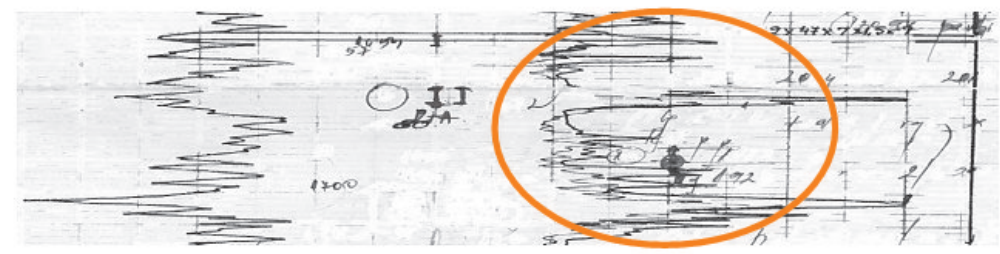

\section{Standard \\ Electrical Log}

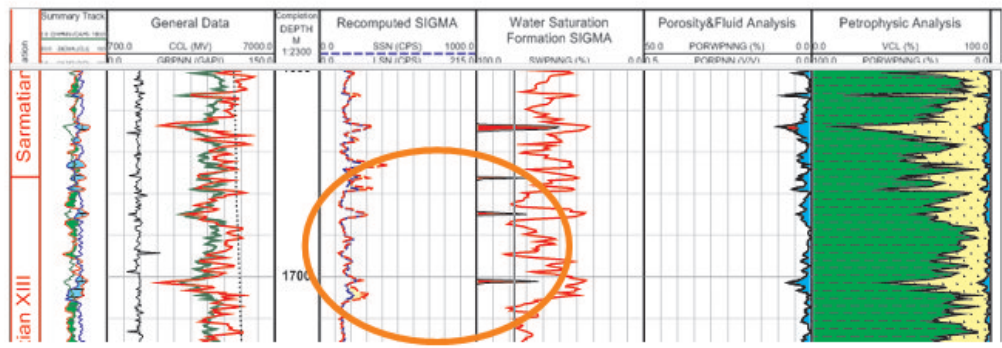

PNN

Interpretation

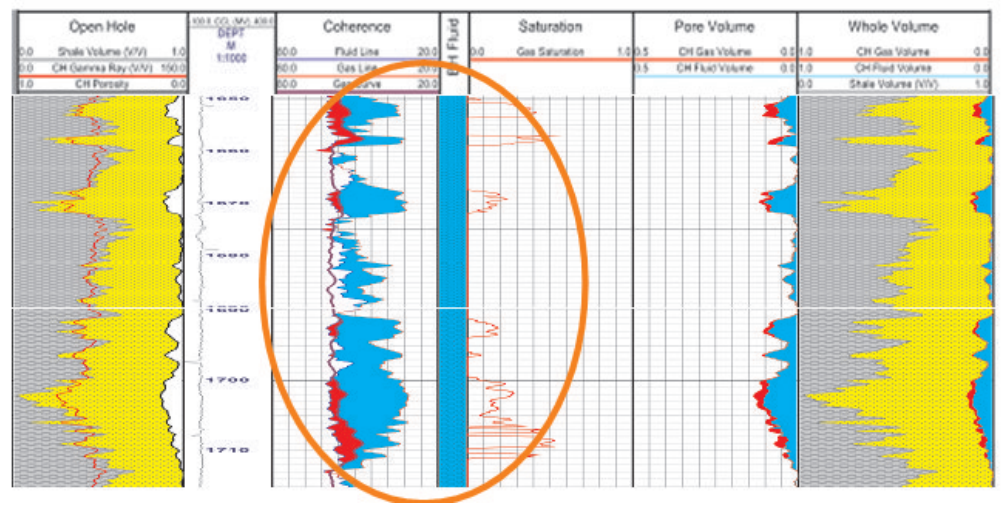

Raptor

N-Vision

Interpretation

Fig. 3. Standard Electrical Log, PNN Log and CRE Log at well C 


\section{CONCLUSIONS}

Based on the above consideration we tried to apply in our company, the most useful geophysical methods available for cased holes, as PNN and CRE, considering that the reservoirs we refer are depleted reservoirs.

These new investigation methods helped us to evaluate well integrity, improve reservoir management, and scan the well for bypassed production before plugging and abandoning. These investigations are also key diagnostic tool for workover planning and operations.

The results from investigations exposed above, helped us to identify layers saturated with gas, which after perforation had been confirmed. These results encourage us to continue investigating old wells in the future using these new investigation methods and to apply also new ones, available in the gas industry, for a more accurate evaluation of the petrophysical properties of the reservoir.

\section{REFERENCES}

[1] Schlumberger: Evaluation and Monitoring Reservoirs Behind Casing. Oilfield Review, Summer 2003.

[2] Smolen J.J.: Cassed Hole and Production Log Evaluation. Pennwell Books, 1996.

[3] Weatherford: Casedhole Reservoir Evaluation System - tool manual.

[4] Hotwell: Pulsed Neutron System - technical documentation.

[5] Atlas G.I.P. SA Ploiesti: Pulsed Neutron-Neutron System. 